\section{MS41 O5}

A Synchrotron Diffraction Study of Microscopic Strain in Garnet Solid Solutions C.A. Geiger ${ }^{a}$, M. Dapiaggi ${ }^{\mathrm{b}}$, and G. Artioli ${ }^{\mathrm{b}}$, Institute of Geosciences, University of Kiel, Germany, ${ }^{\mathrm{b}}$ Dipartimento di Scienze della Terra, University of Milano, Italy. E-mail: chg@min.uni-kiel.de

Keywords: Microstrain, Garnet, Synchrotron Radiation Pyrope-grossular garnet, $(\mathrm{Mg}, \mathrm{Ca})_{3} \mathrm{Al}_{2} \mathrm{Si}_{3} \mathrm{O}_{12}$, solid solutions show marked positive deviations from thermodynamic ideality [1]. The enthalpic nonideality, i.e. $\Delta \mathrm{H}^{\mathrm{mix}}>0$, is thought to result from microscopic elastic strain caused by the substitution of differently sized $\mathrm{Ca}$ and $\mathrm{Mg}$ atoms in the triangular dodecahedral site. Although computer simulations indicate this [2], experimental data measuring local structural strain are scarce to nonexistant. It is possible, however, to determine strain associated with sub-stitutional solid solutions by means of peak shape analysis of high-resolution X-ray synchrotron powder diffraction data. This was done using nine well characterized synthetic Py-Gr garnets from diffraction measurements made at $5 \mathrm{~K}$ at the ESRF. The low temperature data help minimize dynamic effects and allow the strain component to be quantified.

The results show that the two end-members Gr and Py have the lowest strain, while the solid solutions display nonlinear structural strain across the binary. The degree of microscopic strain correlates well with the calorimetrically determined macroscopic $\Delta \mathrm{H}^{\mathrm{mix}}>0$. The asymmetric $\Delta \mathrm{H}^{\text {mix }}$ behavior can even be reproduced, where the largest deviations are at Py-rich compositions. It is concluded that positive enthalpies of mixing in Py-Gr garnets are largely due to local elastic strain energies arising from the $\mathrm{Mg}-\mathrm{Ca}$ cation exchange.

Synchrotron radiation provides a powerful experimental method to investigate the nature of strain density in a material and specifically the physcal reasons causing thermodynamic nonideality in solid solutions. Diffraction measurements may even offer an alternative method for the evaluation of $\Delta \mathrm{H}^{\text {mix }}$ when calorimetric measurements can not be undertaken.

[1] Dachs, E., Geiger, C.A., Am. Min., 2006, 91, 894.

[2] Bosenick, A.; Dove, M.T.; Geiger, C.A., Phy. Chem. Min., $2000,27,398$. 